\title{
Determining Factors Influencing E-Government Development in the Developing World: A Case Study of Zambia
}

\author{
Bwalya Kelvin Joseph \\ Department of Information and Knowledge Management
Faculty of Management, University of Johannesburg, Johannesburg, South Africa
}

Correspondence should be addressed to: Bwalya Kelvin Joseph; bwalyakelvinjoseph@gmail.com

Received date: 10 November 2016; Accepted date: 15 November 2016;

Published date: 12 January 2017

Academic Editor: Zaigham Mahmood

Copyright (C) 2017. Bwalya Kelvin Joseph. Distributed under Creative Commons CC-BY 4.0

\begin{abstract}
Understanding the contextual factors that influence e-Government growth is cardinal for informing policy and strategies for e-Government development. Many e-Government researchers have attempted to counter the huge failure rates of e-Government but with minimal success. This paper discusses, with the methodological contours that need to be followed, the determining factors that influence e-Government growth in a given context. The paper explores factor analysis from a multi-dimensional perspective to determine the possible inherent factors that may influence e-Government from multiple vantage points. In order to clearly show what is involved when determining factors influencing e-Government from a methodological perspective, the case of Zambia discussed in this contribution presents a 'hands-on' feel in the utilisation of the proposed procedure. It is hoped that this paper will act as a reference point for researchers and practitioners as they design eGovernment interventions as it will be used as a guiding tool in determining factors influencing e-Government development.
\end{abstract}

Keywords: E-Government, factors, factor analysis, influencing factors, context, adoption, Zambia

\section{Introduction}

E-Government has placed itself as a lever for transformative public administration which is responsive in nature, adaptive and allows citizens to participate in the governance value chains regardless of their status. In its entirety, e-Government entails the use of Information and Communication Technologies (ICTs) by government de- partments in the provision of public services. The implementation of eGovernment enables the facilitation of openness and transparency in public service business value chains, putting in place a cost effective initiative and enabler towards achieving responsive government to citizens' needs and control of corruption in government business as it encourages accountability [4]. The implementation of e-

Cite this Article as: Bwalya Kelvin Joseph (2017)," Determining Factors Influencing E-Government Development in the Developing World: A Case Study of Zambia ", Journal of e-Government Studies and Best Practices, Vol. 2017 (2017), Article ID 143795, DOI:10.5171/2017.143795 
Government looks promising to end corruption and lack of accountability which are endemic+ in Africa and other developing world countries.

With the ever-changing information age, eGovernment has evolved into a platform to promote electronic democracy (eDemocracy) and social welfare. In order for e-Government to be realised, especially in the realm of e-Democracy, there is need for easy platforms which citizens and businesses can easily explore. Depending on the context, an interactive web platform based on Web2.0 technologies may be a good space for stakeholders to meet and exchange ideas.

Since one of the key enablers of eGovernment is technology, there is need for requisite ICT infrastructure for it to survive. For a long time, Africa has been labelled as a 'technological desert' and many prior initiatives for e-Government implementation have failed due to, essentially, lack of requisite infrastructure, low ICT literacy rates, low economic development, and a variety of cultural factors [29]. This has changed, to a less or much extent, because the continent has seen huge investments in ICT infrastructure as erecting the undersea optical cables (e.g. EASSy, TEAMs, West African Cable System (WACS), LION/LION2, etc.), improved ICT literacy rates, revamped interest in investing in ICTs by African governments, huge Internet penetration rates especially propagated by mobile Internet-enabled phones, etc. Limited or non-availability of adequate and appropriate ICT infrastructure and existence of design reality gaps have been identified as one of the key bottlenecks for the success of e-Government. Many of the African governments have been found to promote e-Government merely as rhetoric because of the deeprooted secrecy to information, which is in most cases, engulfed into the cultural milieu of African nations. Some have implemented e-Government simply out of a desire onto the bandwagon of countries having implemented it. The propensity to failure of e-Government projects is exacerbated by differing interests of the many actors involved in the e-Government establishment [12].
Many e-Government projects have failed because of designing e-Government solutions without clear reference to the context in which it is to be implemented [13]. 'Copying and pasting' e-Government designs that worked elsewhere means that responsive designs are not considered. In order to design responsive e-Government, the design should be influenced by the contextual factors from the area in which it is to be implemented. Because of the importance that understanding factors is in as far as e-Government design is concerned, many studies have investigated the factors influencing failure of e-Government solutions [5].

This paper aims to determine the factors that influence e-Government development in a developing world taking Zambia as Case Study. It is anticipated that the identified factors will be used to guide designs of e-Government implementation strategies especially for countries in the developing world contexts. The paper is arranged as follows: the next section outlines the value and benefits of e-Government, then the next section discusses the characteristic of e-Government as a public good, and finally presents the Case Study of Zambia to understand the key factors influencing eGovernment.

\section{The value of e-Government}

In order to understand the value of $\mathrm{e}$ Government, it is important to clearly define what it entails. E-Government is the use of technologies to provide citizens with information and services to enhance their participation in democratic institutions and processes [17]. Alternatively, eGovernment can be defined as the utilisation of ICTs towards transformation of internal and external public sector relationships with a view to optimise public service delivery and citizens' participation [31]. EGovernment presents itself not only as a pathway to access or engage with government but also to bring about developmental opportunities to the local communities as a whole [29].

The move towards e-Government was motivated by the many limitations of traditional public services which are character- 
ised with rigidity, proceduralism, red-tape, inefficiency and incapability to serve clients. E-Government is a catalyst or tool for administrative reform [15]. The use of technology in public service delivery facilitates increased operational efficiency because the overall cost of public service delivery is reduced; and improved (better quality) public services are provided by government departments [10]. Using technology in the e-Government domain ensures that public service delivery is brought to the doorsteps of the people. Further, the use of ICTs allows even the socially disadvantaged individuals to be included (e-Inclusion) into and participate in the decision-making and governance value chains.

It is worth mentioning that corruption which is endemic in Africa and most of the developing nations can be approached principally using two main ways: through administrative reform (the idea of eGovernment to promote openness), law enforcement and the social change approach. These three approaches can be enforced in tandem if e-Government is appropriately and contextually designed.

Transparency and openness to information are the hallmarks of Freedom of Information (FOI) which has been recognised as one of the key focuses in the new understanding of e-Government [4]. There is no degree of transparency and accountability with regards to public service delivery which can be achieved if FOI is not enacted. Transparency is the backbone of any democracy which can be achieved by providing direct access to government information the citizens are interested in so that they can monitor government performance [18]. With the introduction of ICTs in the public administration value chains, corruption practices have been unearthed. Many countries in the world (e.g. India, South Korea, Philippines, Pakistan, Chile, USA) have claimed success in using ICTs in their government contexts with a goal to reducing corruption [4]. It can thus be posited that ICTs are an enabler that helps countries enforce their laws to fight corruption and lack of accountability amongst government workers. This can be achieved if ICTs are embedded into government's business processes so that there is universal access to government information and decisions through accessible ease-to-use technology platforms. Anti-corruption system called the Online Procedures Enhancement for civil application (OPEN) in the Seoul Metropolitan Government [18].

The study presented in [12] posits that the application of networks concepts such as partner selection, achievement of network goals, institutionalisation processes, network structuring and incentive design can culminate into the realisation of anticipated benefits of e-Government. Since public administration continually reveals itself as a multi-dimensional phenomenon with complex interlinked factors, it is inconceivable to look at e-Government as a panacea to all the problems public administration faces [8].

\section{E-Government for the Public Good}

The over-emphasis for a need to re-think public administration throughout the world especially in the light of massive adaptive ICTs hasn't sprung ex nihilo from without a careful consideration of a need for responsible public service governance. There is urgent need to combat corruption, desired responsive governments to citizens' needs and ability of governments to be mainstreamed into the global socioeconomic value chains, participatory and collaborative governance, and to have transparent/open governance value chains [23]. The key understanding with regards to accountability and effectiveness of public services is that any public administration endeavour should benefit the general public in the spirit of 'public good'.

In order to realise the conceptualisation of e-Government as a public good, there is need for government information to be placed in the public domain so that all necessary stakeholders participate in the governance value chains and decision-making. In order to accomplish the aspirations espoused in 'e-Government as a public good', the concept of Open Government Data comes in. Open Government data entails putting in the public domain all government data so that different stakeholders can have access to it and use it as reference 
for decision-making. This, therefore, ushers in paradigmatic changes where there is a reduction in the cost of public service provision and improvement of the quality of internal public administration processes [11].

E-Government should not be designed strictly from a public-good perspective but should clearly establish a business case whence all the e-Government solutions are going to be designed. This means that there needs to be a balance between the business ramifications of e-Government and its role as a public initiative aimed for serving public interests. In order to check whether eGovernment serves its purpose, proper eGovernment discourses are evaluated using a public value framework which is based upon the return or benefit obtained from the e-Government innovation unlike traditional governance system [36]. The concept of 'public good' is closely related to 'public value'. Public value is a relative abstractive phenomenon because it depends on the individual/entity perceiving public interest and that the notion of value may force actors in the public ecosystem to compete for legitimization, acceptance and hegemony. It is worth mentioning that the concept of 'value' can be looked from several contextual standpoints as the word has multiple meanings and ambiguity [3].

Since the precedence penned by Obama on the need to change the way public administration is done towards more openness, transparency and responsiveness, many governments around the globe have done or are doing the same. This has seen eGovernment not to be looked at as government-as-usual only enabled by the use of ICTs but as participatory governance where all information and decisions are in the public domain. The current understanding is that e-Government will usher in resumes where governance is done on public platforms where all citizens regardless of socio-economic status can participate. This is being facilitated by the many FOIs being propagated in many countries [23].

It should be concluded that e-Government is not only a technical and non-ideological issue but that it is multi-dimensional; it encompasses all aspects of the political and governance discourse. In the past, the development of e-Government has been guided by the supply side forces without necessarily and critically considering the demand side (consumers). In order to understand the general factors that influence success of e-Government, many researchers have investigated factors that influence user adoption and usage (attitudinal determinants) of e-Government. It is these factors that should be at the centre of eGovernment design [35]. Any eGovernment design should consider the contextual factors that may increase the likelihood of success for any e-Government implementation.

\section{E-Government Evolution}

Public administration has been passing through different phases over the years from traditional administration styles where individuals need to visit physical offices to obtain a service to accessing public services through technology platforms (eGovernment). E-Government was ushered into being with the emergence of New Public Management (NPM) whose key auspices are based on promoting accountability, effectiveness and efficiency of public administration. The hallmarks of NPM were promoting efficiency, marketization, accountability, decentralization, and reinventing government so that it is more responsive to the needs of the citizens [24]. Of late, there has been a delve towards Open Government Data (OGD) which argues that government information and decision-making processes should be put in the public domain where individuals regardless of their status can access them. The concept of OGD opines that there should be accountability and transparency in public administration.

The NPM employs different models to achieve its goals. The NPM Managerial Model posits that the role of the state is to provide information and focuses on transactional activities such as tax filing, drivers' licences and for accessing government information. The NPM Consultative Model promotes a limited degree of citizen/business-state interaction where eGovernment is seen as an attempt to link various legacy systems in the governance 
hierarchy. The first point of call for eGovernment implementation is eReadiness which is the ability of an economy to utilise ICTs in order to tap into the different opportunities brought about by the new economy [17]. The NPM Managerial Model posits that the role of the state is to provide information and focus on transactional activities such as tax filing, drivers' licences and for accessing government information. The Consultative Model promotes a limited degree of citizen/businessstate interaction where e-Government is seen as an attempt to link various legacy systems in the governance hierarchy. The type of e-Government design envisaged in this paper is the Participatory Governance Model which aims to ensure that all citizens/businesses regardless of their social standing participate in the design and implementation of e-Government thereby increasing the representative base in the decision-making processes. However, because of changing times in the information environments and landscapes regardless of the contexts, NPM has generally outlived its usefulness due to its diminished anticipated impact on the overall government. Therefore, it is important to have adaptive e-Government solutions designed collaboratively which aim to ensure that managerial policies, technology and people are strongly coupled together.

E-Government research has concentrated on two dimensions - technological (inherent features of technology that determine the impacts of introducing it) and social (human choices within different social structures)) determinism [14]. Based on NPM, Public Service Platforms (PSPs) are a new form of technology platform that support service provision to citizens in an eGovernment framework [28]. The OGD movement has been faced with considerable technical and social barriers that threaten its wider adoption towards being a hallmark for open and responsive government enshrined onto the FOI conceptualisation [7].

The data open movement is swiping across the world with no reservations to developing world contexts with Ghana joining the bandwagon with the Ghana Open Data Initiative (GODI). At the global level, the Global Open Government Partnership
(GOGP) aims to encourage the development and proliferation of multistakeholder governance frameworks. On the other hand, national initiatives such as the GODI aim to advance the principles propagated by GOGP at the national level. The GODI aims to re-connect the supply and demand sides of e-Government in Ghana so that they exchange public information [26].

In order to withstand the changes in the peoples' tastes in as far as accessing public services is concerned, or to move with the ever-changing technologies, and remain relevant in all respects as a public platform-of-choice, e-Government has kept transforming. The transformation is about change and when looked at through the lens of public administration may mean an improvement in the service and a perceivable change which brings about significant difference in the ex-ante and ex post of the transformed entity [3]. There are many variants of e-Government given the changing conceptualisations. For example, because of higher penetration rate of internet-enabled mobile phones, e-Government has transformed into mobile government (m-Government) to create ubiquitous/pervasive access of government information. M-Government has seen rapid growth especially in many of the developing world countries where the mobile penetration rate is higher [32]. With a bid to further link citizens and government and transform their interactions, the concept of Big and Open Linked Data (BOLD) has been conceived [16]. The Internet of Things (IoT) is increasing every day and new innovations appear to make our society more safe and secure, but at the same time threaten individual privacy (Janssen \& van den Hoven, 2015). Web 2.0 platforms are slowly being utilised as e-Government tools especially for activities ranging from open policy-making, customer service to collaborative platforms [33]. The other transition of e-Government has been towards "eGovernment 2.0". E-Government 2.0 entails the use of Web 2.0 technologies into the eGovernment arena. E-Government 2.0 was used in the UK Local Government Authority (UKLGA). 
In advanced e-Government environments, such as South Korea, smart government is now gaining ground. Smartness in the public administration domains entails the enshrinement of creative mix of emerging technologies and the cultivation of an innovation culture which allows timely response to service demands [9]. The core characteristics of smart government are utilising environmentally-friendly ICT, enhancing work productivity, employees' balance of work and life [9].

Given the above, especially with the transformation of e-Government in order to adapt to changing information paradigms, and considering the many benefits that come with e-Government implementation, ignoring the use of ICTs in the public service business processes culminates into a very big opportunity cost.

\section{Theoretical Framework}

In order to understand the factors that influence the proliferation of e-Government in Zambia, it was apparent that the study investigates what motivates adoption and usage of e-Government platforms by the citizens and organisations. Further, a probe into the contextual (environmental) characteristics defining successful eGovernment implementation is presented. This study investigates the initiatives done on the supply to promote e-Government development and looks at the readiness of individuals and businesses to accept technology. The point-of-departure is that when there is equilibrium between the supply and demand sides of e-Government, there is a higher likelihood that the diverse digital opportunities brought about by e-
Government in the realm of public administration will be harnessed.

To understand the individual perceptions of use of ICTs to access information or do business with government, the study utilised the Technology Acceptance Model (TAM). The TAM is premised on the SocioPsychology theory which is a branch of social psychology which examines how people's thoughts, perceptions, feelings, behaviours are influenced by the perceived, actual or imagined presence of other human beings. This means that other than the individual attributes or aspirations of a technology, the propensity and actual adoption of a given technology by a group or another individual can influence the degree to which an individual adopts a technology newly introduced. This is not to assume that the individual perceptions of the individual of the technology can be ignored. In recognisance of the Socio-Psychology theory, the TAM measures attributes centred on the individual. The TAM principally investigates the willingness of individuals to adopt and use a technology. Individuals' the 'Perceived ease of Use' (PEOU) and the 'Perceived Usefulness' (PU) are the major constructs employed by the TAM [34]. PEOU is the perception held by the intended user of the technology on how easy it is to use practically. It is mostly enhanced by the computer self-efficacy and the design attributed of the system/technology deployed. The PU is the degree to which the technology contributes to the wellbeing of the individual. It articulates the level at which the technology introduced contributes to making the work of an individual accomplishable to the desired outputs. The TAM is schematically shown in Figure 1 


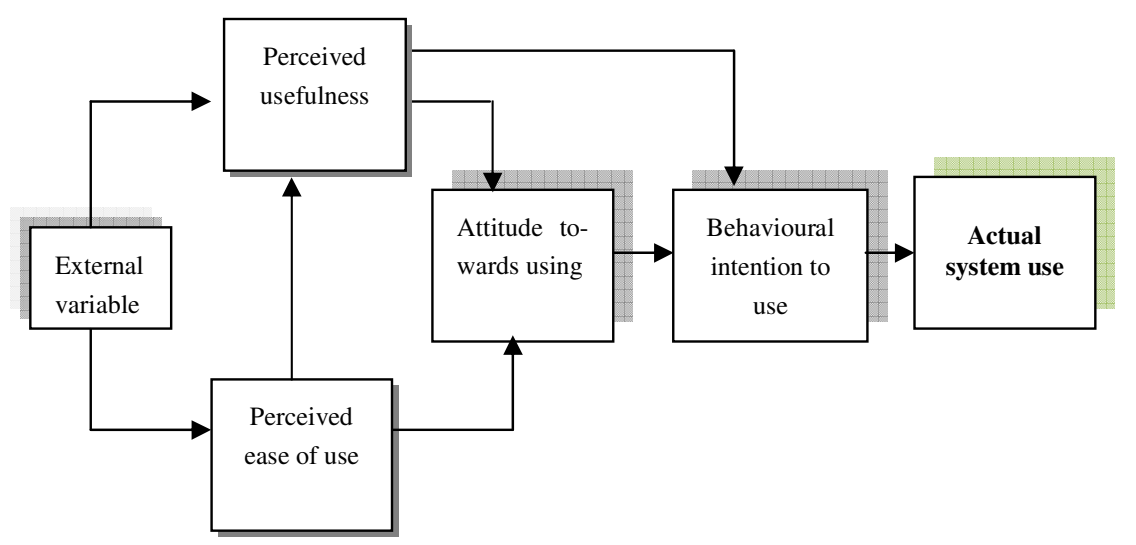

Figure 1: Davis' Technology Acceptance Model (Adapted from: [1])

The TAM has found its usage in different types of industries where technology was introduced for the first time as an enabler to achieve a desired goal, e.g. cellular telephone industry, investigating online consumer behaviour, electronic commerce, World Wide Web adoption and usage, eGovernment implementation, etc. $[19,20$, $21,22,27]$. The choice of the TAM in this study is that, in the context of Zambia, eGovernment is just being introduced and citizens/business perceives it as a new technology platform introduced to revamp public administration. The predictive capacity of the TAM is between 40 and $50 \%$. Although the TAM has been considerably used to measure intention to adopt technology, it has structural inefficiencies as espoused by [2]. Notwithstanding, the TAM was deemed fit as a theoretical lens on which this study was designed. The structuration and Technology Enactment Model (TEM) were used to determine the factors on the supply side.

\section{Methodology}

Using both the positivist and interpretive (quantitative and qualitative) research paradigms, questionnaires (with both closed and open-ended questions) and interviews were used to collect data which were analysed using multivariate analysis [30]. The use of two research paradigms was important because the researcher aimed to understand each of the eGovernment phenomena from two vantage points [25].
The data collection instrument was piloted with 40 individuals and questions that needed attention were rephrased. Individuals with requisite ICT skills and potentially developed computer self-efficacy with the potential to engage in $\mathrm{e}$ Government were targeted. The study population comprised university students, citizens randomly selected, administrators, policy makers, lecturers/researchers, company representatives. The inclusion criterion was that participants needed to be at least 16 years old, was able to read and had accessed the Internet at least once in their lifetime. In the preliminary stages of the research, interviews were conducted with a total of 22 government workers from 5 government ministries and 3 parastatals in order to understand the current status of egovernment implementation in Zambia, what challenges are being faced and what the future prospects are. The interviewees were selected from three tiers of the government hierarchy: four General Workers, seven Line Managers, sectional heads or mid-level management, and 11 Senior Managers and/or policymakers. In the pilot study, 40 people were targeted. In the pilot stage of the study, purposive sampling was employed to identify potential participants. The participants at this stage of the study were selected randomly among the students and academics at the University of Zambia.

The sample frame in this study was well over 3000 participants. The study targeted a possible sample size of 721 due to logistical constraints in carrying out the study.

Bwalya Kelvin Joseph (2017), Journal of e-Government Studies and Best Practices,

DOI: $10.5171 / 2017.143795$ 
Only 411 questionnaires were returned for analysis and eventually only 408 (57\% response rate) were included in the analysis. Standard multiple regression (Kolmogorov-Smirnov and the Shapiro-Wilk tests) was used to analyse the data which were priori checked for normality by checking their fit in the Gaussian normal distribution (see section below). Outliers were removed and data subjected to data transformation using natural logarithmic ramifications. Factor analysis (using multi-colinearity values with factor having $>0.5$ included for analysis) was then conducted, in conjunction with the Kaiser-Meyer-Olkin (KMO) to measure sampling adequacy. After that simple ANOVA tests were conducted to check for $\mathrm{R}$ squared values and degree of variance of each of the factors. Only three
Zambian towns (Livingstone, Lusaka and Kitwe) were included in the study.

\section{Preliminary Tests for Normality}

In order to conduct multivariate analysis on the dataset obtained from the research, it was necessary that the data be subjected to preliminary analysis to determine whether the data followed Gaussian normal distribution curve (i.e. the Bell Curve). This was necessary to determine statistical significance (reliability and validity). Shown in Figure 2 are two illustrations depicting the distribution of the mean and standard deviation from the responses from the study on the availability of appropriate ICT infrastructure.
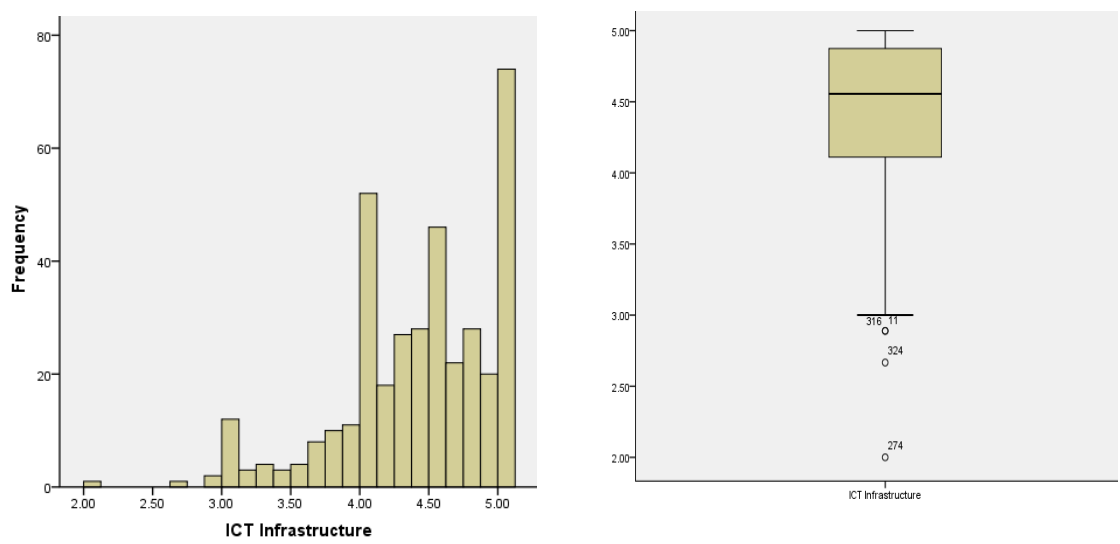

Figure 2: Histogram and Box-plot of 'ICT infrastructure' dataset

It can be observed in Figure 2 that the dataset on 'ICT infrastructure' is shifted to the right (negatively skewed) and the presence of outliers is emphasized on the Box-plot. Cases 324 and 274 are outright outliers. This, therefore, demonstrates that the given dataset obtained from the study does not follow the normal Gaussian distribution 'bell-shaped' form and therefore does not qualify to be included in the multivariate regression analysis. In order to avoid this problem, data transformation of the dataset was necessary.

Using oblique rotation with Kaiser Normalization, restricted factor analysis was per- formed on the dataset so as to obtain the variance coefficients for each of the potential factors. This was necessary to identify which factors to include in the regression model. Oblique rotation derives factor loadings based on the assumption that the factors are correlated; this is probably the case for most measures, and gives the correlation between the factors in addition to the loadings. Factor analysis is made possible by using communalities and the Scree plot to determine the factors with higher communalities. Eigenvalues greater than 1 are included in the analysis and factors with value greater than 0.5 and closer to 1 are chosen by the restricted factor analysis 
methodology. The following three steps were taken using Exploratory Factor Analysis (EFA):

- In the first phase of factor analysis, 15 factors were extracted using 13 iterations after using Principal Axis Factoring as the extraction methodology.

- In the second phase of analysis, Case 9.4.8 was excluded because of low communality $(<0.3)$. Rotation converged after 19 iterations using
Promax with Kaiser Normalization as the rotation methodology. Nine factors were extracted.

- In the third phase, that is, without Case 10.8 , the analysis forced seven factors with restricted EFA.

The seven factors remaining, listed in Table 1 below, were used in the analysis of the citizens' understanding of the anticipated benefits of e-Government applications.

Table 1: Tests for Normality on all measured items

\begin{tabular}{|c|c|c|c|c|c|c|}
\hline & \multicolumn{3}{|c|}{$\begin{array}{l}\text { Kolmogorov-Smirnov } \\
\text { [Lilliefors Significance Cor- } \\
\text { rection] }\end{array}$} & \multicolumn{3}{|c|}{ Shapiro-Wilk } \\
\hline & Statistic & $\mathrm{df}$ & Sig. & Statistic & Df & Sig. \\
\hline 1) ICT_infra & .132 & 374 & .000 & .901 & 374 & .000 \\
\hline 2) PEOU & .142 & 377 & .000 & .972 & 377 & .000 \\
\hline 4) $\mathrm{PU}$ & .117 & 401 & .000 & .930 & 401 & .000 \\
\hline 5) Comp_SE & .178 & 405 & .000 & .880 & 405 & .000 \\
\hline $\begin{array}{ll}5) & \text { Actu- } \\
\text { al_usage } & \end{array}$ & .129 & 405 & .000 & .899 & 405 & .000 \\
\hline 6) Trust & .149 & 377 & .000 & .951 & 377 & .000 \\
\hline 7) Cont_Usage & .147 & 374 & .000 & .924 & 374 & .000 \\
\hline
\end{tabular}

Table 1 shows the application of the Kolmogorov-Smirnov and the Shapiro-Wilk test to further test for normality in the dataset viz:

ICT_infra = ICT infrastructure; PEOU = Perceived Ease of Use; PU = Perceived Usefulness; Comp_SE = Computer self-efficacy; Actual_Usage = Actual usage of eGovernment applications; and Cont_Usage = continuous usage of e-Government applications

The Kaiser-Meyer-Olkin Measure of Sampling Adequacy was performed to establish whether the identified factors were statistically significant. The results showed that the KMO result exceeded 0.5 and was closer to 1 implying that all items were statistically significant. The Bartlett's Test of Sphericity tested the null hypothesis that the correlation matrix is an identity matrix. With these tests, it was not apparent that it was statistically correct to subject the dataset to statistical analysis.

\section{Findings}

Table 2 presents the overall characteristics of the participants in this study. Most of the respondents were in the 22-49 age group meaning that they could not independently engage in e-Government applications. 
Table 2: Characteristics of participants

\begin{tabular}{|l|c|}
\hline \multicolumn{1}{|c|}{ Parameter } & Subject (N = 409) \\
\hline Age (mean, range) & $26-49,16-70$ \\
\hline Gender (male, female, missing) & $220,164,24$ \\
\hline Race/ethnicity (African, other) & 338,21 \\
\hline Native language (English, Bemba, Tonga, Nyanja, & $16,121,93,77$, \\
other) & 102 \\
\hline & $87,22, \quad 128$, \\
Education (PhD, Masters, Bachelors, other) & 312,97 \\
\hline Employment status (employed, unemployed) & \\
\hline
\end{tabular}

The descriptive statistics on the awareness and usefulness of e-Government solutions by the participants shows that most participants were aware of e-Government solutions in Zambia. The data included in the analysis are statistically significant as the non-parametric Spearman's correlation were at 0.01 and 0.01 levels of significance. The participants were in agreement that eGovernment inculcates efficiency and effectiveness in the public administration value chains. Further, participants attested to the fact that e-Government is advantageous for the following reasons: advertising government services online, applications for land (land allocations), applications for visas to other countries, birth and death registration, checking up examination results (eLearning), application for employment, public project monitoring, knowledge shar- ing, electronic payment of services, citizen registration systems, information and knowledge sharing amongst government departments, and electronic commerce.

\section{Factor Correlation and Regression Equation}

In order to understand how each of the identified factors impact on another towards effective adoption of e-Government platforms, correlation and regression analysis was performed. After data transformation to avoid outliers, regression was achieved using the logarithmic value of 'PU' (Log_PU). Table 3 presents the results of Pearson's correlation acted on the dataset. All requested variables on PEOU were entered and the Log_PU was the dependent variable.

Table 3: Pearson's correlations on PEOU on PU $(\mathrm{N}=408)$

\begin{tabular}{|l|l|l|l|}
\hline \multirow{2}{*}{ Pearson Correlation } & Log_PU & PEOU \\
\hline \multirow{2}{*}{ Sig. (1-tailed) } & Log_PU & 1.000 & -.371 \\
\cline { 2 - 4 } & PEOU & -.371 & 1.000 \\
\hline \multirow{2}{*}{$\mathbf{N}$} & Log_PU & - & .000 \\
\cline { 2 - 4 } & PEOU & .000 & - \\
\hline & Log_PU & 401 & 377 \\
\cline { 2 - 4 } & PEOU & 377 & 377 \\
\hline
\end{tabular}

Table 4 illustrates the degree of variance (Predictive value $-\mathrm{R}^{2}$ ) of PEOU on PU. [ $\mathrm{R}^{2}=$ the coefficient of determination, showing the degree of variance predictor variable contributes to the other variable where correlation exists. $\mathrm{R}^{2}$ value of 0.137 means that the prediction capacity of the regression model obtained from this dataset explains $13.7 \%$ of the variation in the outcome is determined by the predictor variable. 
Table 4: Model Summary

\begin{tabular}{|c|c|c|c|c|}
\hline Model & $\mathbf{R}$ & $\begin{array}{c}\mathbf{R} \\
\text { Square }\end{array}$ & $\begin{array}{c}\text { Ad- } \\
\text { justed } \\
\text { Square }\end{array}$ & $\begin{array}{c}\text { Std. Er- } \\
\text { ror of the } \\
\text { Estimate }\end{array}$ \\
\hline 1 & $.371^{\mathrm{a}}$ & .137 & .135 & .13897 \\
\hline
\end{tabular}

Table 5 shows the analysis of variance in the dataset. From the ANOVA tests con- ducted, it is evident that the dataset is statistically significant.

Table 5: Analysis of Variance (ANOVA)

\begin{tabular}{|c|l|c|l|c|l|l|}
\hline \multicolumn{2}{|c|}{ Model } & $\begin{array}{c}\text { Sum of } \\
\text { Squares }\end{array}$ & df & $\begin{array}{c}\text { Mean } \\
\text { Square }\end{array}$ & F & Sig. \\
\hline \multirow{2}{*}{1} & Regression & 1.153 & 1 & 1.153 & 59.702 & $.000^{\mathrm{a}}$ \\
\cline { 2 - 7 } & Residual & 7.243 & 375 & .019 & & \\
\cline { 2 - 7 } & Total & 8.396 & 376 & & & \\
\hline
\end{tabular}

A regression analysis, predicting Log_PU from PEOU, was highly statistically significant with:

$$
F(1)=59.702, p<.001
$$

After the data transformation, the outliers were removed from the dataset and the data were ready for statistical analysis. Fig- ures 3 below show the Gaussian normal fit for 'Continuance Usage' on all other variables and the standardized residue of 'Continuance Usage' on all other variables (the six factors identified after factor analysis). 'Continuance Usage' measured the likelihood that the adopters of technology may continue using the adopted technology way after adoption.
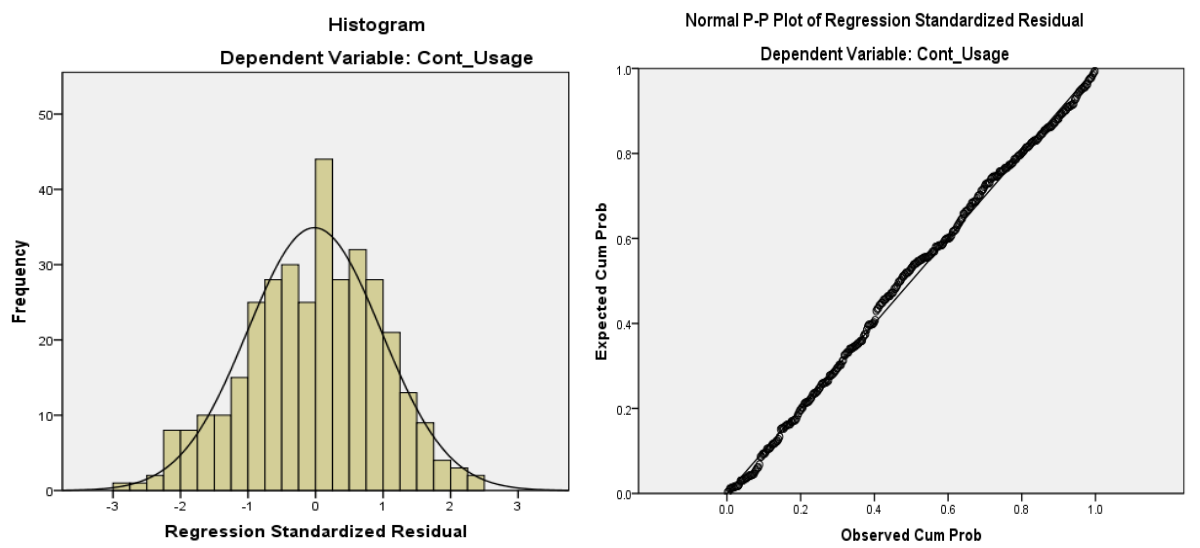

Figure 3: Gaussian normal data fit and the P-P plot for standardized residue of Continuance Usage on all other variables

From Figure 3, it is evident that the data follow a linear regression trajectory and hence confirm the validity of the multivariate analysis used in this study. After a rigorous factor analysis procedure, six constructs were found to be key for the success of e-Government implementation in the Zambian context. A series of correlation analysis and ANOVA tests were conducted on the dataset and it was found each of the identified factors correlated with one of the aspects of the other factors. 
To further understand the variance of each factor, the R2 value was computed for each of the factors. The overall value of $23.1 \%$ $(\mathrm{R} 2=0.231)$ variance with statistical significance $F(1)=17.652, \mathrm{P}<.001$ was obtained. This means the predictor constructs accounted for $23 \%$ of the factors for the likelihood that citizens will engage in eGovernment.

This empirical research has shown that citizens perceived e-Government important as over 75 of the participants ascertain that e-Government can bring public information closer to the people. A further $68 \%$ are in agreement that e-Government platforms may be used for paying tax and buying services from utility companies may shorten the wait-cycle for e-Government services, reduce the cost of public service and may generally improve the whole public administration establishment towards accomplishing its desired goals. Using thematic analysis, the following were the key factors that influence e-Government successful development:

- Anticipated users of e-Government platforms need to be aware of eGovernment solutions or the intention of the government agencies to implement e-Government beforehand. From this study, $49 \%$ of the study participants were not aware of e-Government services in Zambia and $21 \%$ showed total ignorance of what e-Government is.

- Anticipated e-Government users need to be convinced on the importance and usefulness of e-Government as an innovation to revamp the public service.

- The platforms on which e-Government solutions are designed need to be easyto-use so that many people who may have limited ICT skills may be included in the e-Governance value chains. There is need to include user-friendly e-Government platforms to cater for users' limited experience in interacting with ICT platforms and the Internet. It is not a secret that many of the people in the developing countries may have limited ICT skills which may not be enough for them to appropriately engage in e-Government.

- In order to engage in e-Government, citizens need to first trust the government as a governance entity and secondly trust the integrity of the information on its web platforms. A total of $84 \%$ of the study participants indicated that there are no security policies to guide interactions in the online environments. Therefore, it is difficult to trust government information on online platforms.

- Infrastructural challenges such as limited ICT infrastructure, expensive Internet access points, and lack of wellinstitutional establishments to guide eGovernment implementation prevent users from accessing e-Government implementation.

- Inclusion of local or locally-relevant content in e-Government and content in local languages so that the goal towards universal e-Inclusion is achieved.

From the empirical study, PEOU and PU positively contribute to the realization of CU (+ $0.137 \times 2+0.046 \times 3)$ thereby confirming the notion that they are two important factors that influence individuals' willingness to engage in technology utilization (Davis, 1989) and further confirm the later studies that attempted to validate the TAM $[27,34]$. It is anticipated that any design of e-Government interventions should take cognisance of the different factors discussed above that negatively influence eGovernment development.

In order to overcome the paucity in ICT infrastructure in Zambia and promote universal access of e-Government platforms, the following interventions have been pursued by the government and the relevant eGovernment stakeholders. Some interventions done include: launching of the ICT policy in 2007 to facilitate mainstreaming of ICTs in the different socio-economic frameworks; Introduction of the Payroll Management and Establishment Control 
(PMEC) system with a bid of improving information flows amongst different government departments; Computerization of the Customs system at the Zambia Revenue Authority through the Automated System for Customs Data (ASYCUDA), linking of eGovernment to the Public Service Reform Programme (PSRP) aiming for efficient and effective public service delivery, reengineering the public service business process through the Public Service Capacity Building Project (PSCAP), etc. Although these interventions are being put in place, there are poor ICT infrastructures and no dedicated e-Government implementation strategy.

The study participants complained on the expensive Internet cost in Zambia and posited that implementation of e-Government will be very difficult. In order to bring down the costs to Internet access, there has been significant reduction of cost and redtape in the setting up of Internet access points by the Internet Service Providers (ISPs). This has been achieved by the liberalisation of the international gateway in 2010. Under the ICT Act of 2009, with the goal of promoting faster growth in Internet penetration, the government changed the licensing regime for ISPs. Over a year, more than 600,000 people have access to the Internet thereby increasing e-Inclusion in the realm of universal access. However, the empirical study showed that there are no context-aware policies and no appropriate institutional and regulatory frameworks to foster requisite development of eGovernment in the Zambian context.

Given the foregoing, it is evident that there are requisite initiatives that have been or are being put in place to ensure that eGovernment thrives in Zambia. However, the weakest link lies on the demand side as there are no direct and deliberate interventions to counter the limitations on the demand side outlined in this empirical study. Therefore, it can be posited that the desired equilibrium between the supply and demand sides of e-Government is not achieved. It follows that there are a lot of interventions that need to be done if eGovernment were to succeed in Zambia.

\section{Conclusion}

This paper has explored the fundamental concepts of e-Government especially focusing on understanding the factors that influence successful e-Government implementation. Understanding is that e-Government is a very costly undertaking and therefore it is important that the likelihood that it would fail is reduced as much as possible. The key benefits of e-Government in as far as NPM and OGD are concerned have been explored. E-Government contributes a great deal to the new public administration agenda by ensuring that the cost for public service delivery is greatly reduced, there is efficiency and effectiveness in the provision of public services, e-Inclusion is appropriately facilitated, citizens and businesses are rightly included in the decisionmaking processes, transparency and accountability is encouraged and the government responds to the needs of the citizens. It can be seen that e-Government evolves quickly and therefore its design needs to ensure that it uses adaptive platforms which can easily change to be abreast with the emerging demands of technology, people and public service.

It can be concluded that a majority of the consumers of e-Government services, mostly those in the upper level of the society - probably those in positions of administration - are aware and willing to adopt eGovernment which will in the long run culminate into improving governance and the fight against corruption. However, there are no requisite interventions to ensure that there is global knowledge of eGovernment and that the visible limitations among the would-be users of eGovernment are addressed. E-Government designers need to consider the limitations articulated in this study in as far as eGovernment is concerned. The major limitation of this study is that its results may not be statistically representative of Zambia's population and therefore cannot guarantee statistical generalisations. Although this is the case, some insights can be drawn from the results presented in the paper. 


\section{References}

1. Ajzen I, (1991), The theory of planned behaviour. Organisational Behaviour and Human Decision Processes, 50(2), 179-211.

2. Bagozzi R P, (2007), The legacy of the technology acceptance model and a proposal for a paradigm shift, Journal of the Association for Information Systems, 8(4), 244-254.

3. Bannister F and Connolly R, (2015), The great theory hunt: Does e-government really have a problem? Government Information Quarterly, 32, 1-11.

4. Bertot J C, Jaeger P T and Grimes J M, (2010), Using ICTs to create a culture of transparency: E-government and social media as openness and anti-corruption tools for societies, Government Information Quarterly, 27, 264-271.

5. Bwalya K J and Healy M, (2010), Harnessing e-Government Adoption in the SADC Region: a Conceptual Underpinning. Electronic Journal of e-Government, 8(1), 23-32.

6. Davis F, (1989), Perceived Usefulness, Ease of Use, and User Acceptance of Information Technology. MIS Quarterly, 13(3), 319- 339.

7. Dawes S S, Vidiasova L and Parkhimovich 0, (2016), Planning and designing open government data pro-grams: An ecosystem approach. Government Information Quarterly, 33(1), 15-27.

8. Elkadi H, (2013), Success and failure factors for e-government projects: A case from Egypt, Egyptian Informatics Journal, 14, 165-173.

9. Eom, S-J., Choi, N., \& Sung, W. (2016). The use of smart work in government: Empirical analysis of Korean experiences, Government Information Quarterly, $\mathrm{xxx}, \mathrm{xxx}-$ $\mathrm{xxx}$. In press.

10.Gil-Garcl'a J R and Pardo T A, (2005), Egovernment success factors: Mapping practical tools to theoretical foundations, Gov- ernment Information Quarterly, 22, 187216.

11.Gonzalez-Zapata F and Heeks R, (2015), The multiple meanings of open government data: Understanding different stakeholders and their perspectives, Government Information Quarterly, 32 (4), 441-452.

12.Guha J and Chakrabarti B, (2014), Making e-government work: Adopting the network approach, Government Information Quarterly, 31 (2), 327-336.

13. Heeks R, (2003), "Most eGovernmentfor-Development Projects Fail: How Can Risks be Reduced?" iGovernment Working Paper Series, Paper no. 14.

14.Heeks R and Bailur S, (2007), Analyzing e-government research: Perspectives, philosophies, theories, methods, and practice, Government Information Quarterly, 24, 243-265.

15.Helbig N, Gil-García J R and Ferro E, (2009), Understanding the complexity of electronic government: Implications from the digital divide literature, Government Information Quarterly, 26(1), 89-97.

16.Janssen $M$ and van den Hoven J, (2015), Big and Open Linked Data (BOLD) in government: A challenge to transparency and privacy? Government Information Quarterly, 32, 363-368.

17.Joseph S, (2014), Development and validation of a framework for egovernment readiness measurement, (21053794), Unpublished Master of Technology degree in Information Technology at Durban Institute of Technology, http://ir.dut.ac.za/handle/10321/1189 , Accessed 10 June 2016.

18. Kim S C, Kim H J and Lee H J, (2009), An institutional analysis of an e-government system for anti-corruption: The case of OPEN. Government Information Quarterly, $26,42-50$.

19.Koufaris M, (2002), Applying the technology acceptance model and flow theory 
to online consumer behaviour, Information Systems Research, 13(2), 205-223.

20.Kwon H, (2000), A test of the technology acceptance model: the case of cellular telephone adoption, Proceeding of the $33^{\text {rd }}$ Annual Hawaii International Conference on System Sciences, Big Island, HI, USA.

21.Legris $\mathrm{P}$, Ingham $\mathrm{I}$ and Colerette $\mathrm{P}$, (2003), Why do people use information technology? A critical review of the Technology Acceptance Model. Information Management, 40(3), 191-204.

22.Liang H, Xue Y and Byrd T A, (2003), PDA usage in healthcare professionals: testing an extended technology acceptance model. International Journal of Mobile Communications, 1(4), 372-389.

23.McDermott P, (2010), Building open government, Government Information Quarterly, 27, 401-413.

24.Navarra D D and Cornford T, (2012), The State and Democracy After New Public Management: Exploring Alternative Models of E-Governance, The Information Society, 28(1), 37-45

25. Ngulube $\mathrm{P}$, Mokwatlo $\mathrm{K}$ and Ndwandwe S, (2009), Utilisation and prevalence of mixed methods research in library and information research in South Africa 20022008. South African Journal of Libraries and Information Science, 75(2), 105-116.

26.Ohemeng F L K and Ofosu-Adarkwa K, (2015), One way traffic: The open data initiative project and the need for an effective demand side initiative in Ghana, Government Information Quarterly, 32(4), 419428.

27.Pavlou P, (2003), Consumer acceptance of electronic commerce: Integrating trust and risk with the technology acceptance model. International Journal of Electronic Commerce, 7(3), 101-134.

28. Ranerup A, Henriksen H Z and Hedman J, (2016), An analysis of business models in Public Service Platforms, Government Information Quarterly, 33, 6-14.

29.Rorissa A and Demissie D, (2010), An analysis of African e-Government service websites,Government Information Quarterly, 27, 161-169

30.Salant P and Dillman D A, (1994), How to Conduct Your Own Survey, New York: Wiley.

31.Sarrayrih M A and Sriram B, (2015), Major challenges in developing a successful egovernment: A review on the Sultanate of Oman, Computer and Information Sciences, $27,230-235$

32.Serra L C, Carvalho L P, Ferreira L P, Silva Vaz J B and Freire A P, (2015), Accessibility Evaluation of E-Government Mobile Applications in Brazil,Procedia Computer Science, 67, 348 - 357.

33.Sivarajah U, Irani Z and Weerakkody V, (2015), Evaluating the use and impact of Web 2.0 technologies in local government, Government Information Quarterly, 32, 473-487.

34.Venkatesh V, Moris M G and Davis G B, (2003), User acceptance of information technology: Toward a unified view, MIS Quarterly, 27(3), 425-478.

35.Verdegem P and Verleye G, (2009), User-centered E-Government in practice: A comprehensive model for measuring user satisfaction, Government Information Quarterly, 3, 487-497.

36.Yıldız M and Saylam A, (2013), Egovernment discourses: An inductive analysis, Government Information Quarterly, 30, 141-153. 
Index

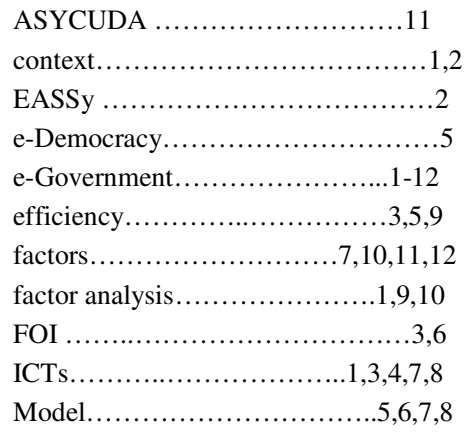

New Public Management..............5

Open Government..................4,5,6

optical cable..........................2

Public Good........................2, 4

PSRP.................................11

Regression ........................9

TAM $\ldots \ldots \ldots \ldots \ldots \ldots \ldots \ldots \ldots . . . \ldots, 8,11$

TEAMs .............................

value........................ 1,2,3,4,5,9

WACS ..............................2

Zambia...........2,3,7,8,9,10,11,12,13

Bwalya Kelvin Joseph (2017), Journal of e-Government Studies and Best Practices, 